\title{
Drinking and the brain: careful selection of research participants required
}

\author{
Elizabeth Avegno • Carl Hart
}

Received: 26 April 2014 / Accepted: 20 May 2014 / Published online: 13 July 2014

(C) Springer-Verlag Berlin Heidelberg 2014

This letter to the editor is in response to the following publication:

Cheetham, A., Allen, N. B., Whittle, S., Simmons, J., Yücel, M., and Lubman, D. I. (2014). Volumetric differences in the anterior cingulate cortex prospectively predict alcohol-related problems in adolescence. Psychopharmacology, DOI: 10. 1007/s00213-014-3483-8.

We read with interest the recent article by Cheetham et al. (2014) examining brain structure of adolescents and the potential relationship with developing problematic drinking behavior. The data seem to indicate that anterior cingulate cortex (ACC) volume predicts the development of alcohol-related problems. The authors should be commended for conducting a longitudinal study in order to investigate this timely and important research question. And while there are multiple merits associated with this well-conducted study, we felt a few concerns warrant further attention.

First, the study did not include nondrinkers, making it impossible to determine whether ACC volume predicts problematic drinking behavior in all adolescents. If nondrinkers were included in the analysis and the findings held up, then our confidence in the conclusions

\footnotetext{
E. Avegno $(\bowtie)$

Department of Pharmacology, Columbia University, 630 W 168th

St., New York, NY 10032, USA

e-mail: ema2159@columbia.edu

C. Hart

Departments of Psychology \& Psychiatry, Columbia University, 401D Schermerhorn, 1190 Amsterdam Avenue MC: 5501, New York, NY 10027, USA
}

drawn would be substantially increased. Second, given the far-reaching implications of the conclusions put forth by the authors, the significant difference in marijuana use between the groups, even though acknowledged by the authors, hampers our ability to meaningfully interpret these results. Marijuana users have been shown to be more impulsive (Solowij et al. 2012) and to display altered ACC activity (Gruber et al. 2012; for review, see Lisdahl et al. 2013). Therefore, in order to accept the conclusions stated by the current authors, a more careful selection of research participants would be required.

Conflicts of interest The authors do not report any conflicts of interest.

\section{References}

Cheetham A, Allen NB, Whittle S, Simmons J, Yücel M, Lubman DI (2014) Volumetric differences in the anterior cingulate cortex prospectively predict alcohol-related problems in adolescence. Psychopharmacology. doi:10.1007/s00213-0143483-8

Gruber SA, Dahlgren MK, Sagar KA, Gönenc A, Killgore WDS (2012) Age of onset of marijuana use impacts inhibitory processing. Neurosci Lett 511(2):89-94

Lisdahl KM, Gilbart ER, Wright NE, Shollenbarger S (2013) Dare to delay? The impacts of adolescent alcohol and marijuana use onset on cognition, brain structure, and function. Front Psychiatr 53(4):119

Solowij N, Jones KA, Rozman ME, Davis SM, Ciarrochi J, Heaven PC, Pesa N, Lubman DI, Yücel M (2012) Reflection impulsivity in adolescent cannabis users: a comparison with alcohol-using and non-substance-using adolescents. Psychopharmacology 219(2): $575-586$ 